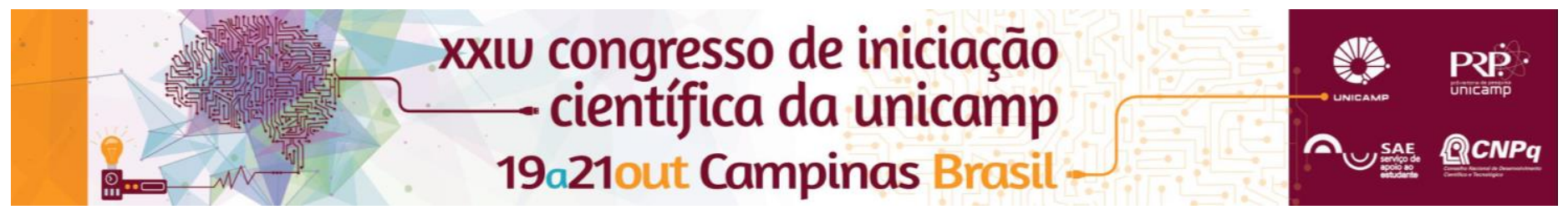

\title{
Síntese e caracterização de grafeno e aplicação em eletrólitos poliméricos gel para células solares.
}

\section{Stephanie Louise Goulart Dáquina*, Paulo Ernesto Marchezi and Ana Flávia Nogueira.}

\section{Resumo}

Este trabalho constituiu na preparação e caracterização de grafeno para aplicação em células solares sensibilizadas por corante (DSSC). O grafeno foi obtido através da esfoliação eletroquímica do grafite. Também foram sintetizadas nanofitas de grafeno (GNR - do inglês, graphene nanoribbons) por meio da abertura de nanotubos de carbono (SWCNT).

\section{Palavras-chave:}

Grafeno, eletrólito polimérico gel, células solares.

\section{Introdução}

As DSSC típicas possuem problemas de durabilidade pois utilizam eletrólitos líquidos, contendo o par redox 1 $-/_{3}{ }^{-}$, que pode causar corrosão do eletrodo além do vazamento do próprio eletrólito ${ }^{1}$. Uma alternativa promissora é substituir o eletrólito líquido por um eletrólito sólido ou gel, como os polímeros. Os maiores problemas enfrentados pela utilização de eletrólitos gel resultam da baixa difusão iônica, devido à elevada viscosidade do meio, problemas com o preenchimento do fotoeletrodo poroso e elevada resistência de transferência de carga no contra eletrodo ${ }^{2}$.

O grafeno, uma única camada de carbono empacotado numa rede hexagonal, é um material promissor na aplicação em sistemas relacionados à energia, como células solares. Para isso, os compostos de grafeno podem ser misturados com polímeros formando compósitos $^{3}$, além de aplicações como eletrodos em dispositivos fotovoltaicos. Este trabalho constitui na preparação e caracterização de grafeno para aplicação em células solares sensibilizadas por corante (DSSC) utilizando eletrólito polimérico gel.

\section{Resultados e Discussão}

Sintetizou-se grafeno eletroquimicamente, de acordo com o procedimento proposto por Deng e col. ${ }^{4}$. Também foram produzidos GNRs por meio da funcionalização de nanotubos de carbono com hidroxila e carboxila, seguida de maceração para a abertura de SWCNTs. A Figura 1 (a) ilustra os 50 ciclos de voltametria cíclica realizados para a esfoliação eletroquímica do grafite. Durante a esfoliação o eletrodo de grafite cresce e chega a dobrar de tamanho. O pico de redução em torno de $-0,8 \mathrm{~V}$ indica o nível de esfoliação, observa-se que, enquanto o número de ciclos aumenta, esse pico se torna cada vez mais pronunciado, o que pode ser relacionado com o nível de esfoliação.

$\mathrm{Na}$ Figura 1(b), observa-se um pico bastante pronunciado em torno de $2 \theta=26^{\circ}$, referente ao plano (002), que após a esfoliação diminuiu de intensidade (EGraf). Isso mostra a perda a cristalinidade do grafite. Esses resultados mostram que a obtenção de grafeno a partir da esfoliação de grafite de lápis realizou-se de forma bem sucedida. A Figura 2 mostra as imagens de TEM dos SWCNTs puros e SWCNTs parcialmente ou completamente abertos (GNR). Podemos observar que foi possível a obtenção do material pelo método proposto e esse material será aplicado em células solares sensibilizadas por corante.

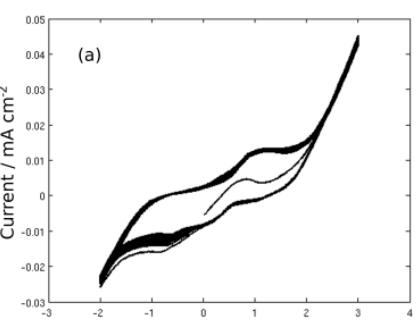

Potential / V

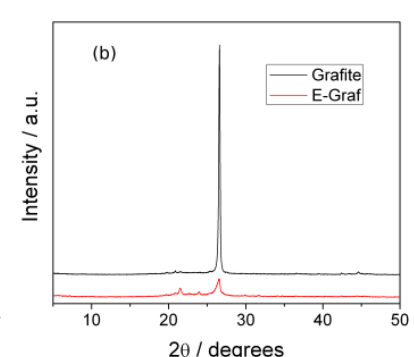

$2 \theta /$ degrees
Figura 1: (a) Voltamograma cíclico da esfoliação eletroquímica e (b) Difratogramas de raios $X$ do grafeno obtido por esfoliação eletroquímica (E-Graf), a partir do grafite de lápis (Grafite).

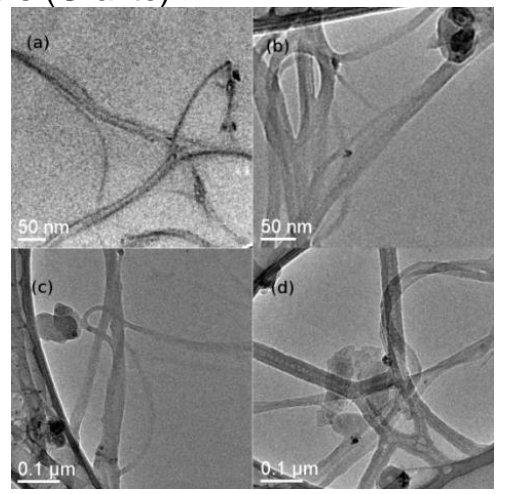

Figura 2: Imagens de TEM dos (a) SWCNT puros e (bd) SWCNTs parcialmente ou completamente abertos.

\section{Conclusões}

Concluiu-se que os resultados se apresentaram satisfatórios. Com a esfoliação eletroquímica do grafite, utilizando um grafite de lápis comercial, foi possível obter um produto parecido com grafeno. E, por fim, foi possível realizar a abertura dos SWCNTs utilizando-se o método proposto.

\section{Agradecimentos}

Agradeço ao programa Pibic, pela bolsa, ao CNPq e FAPESP pelos auxílios financeiros ao laboratório e à Unicamp pela infraestrutura.

${ }^{1}$ Chung, I.; Lee, B.; He, J.; Chang, R. P. H.; Kanatzidis, M, G. Nature. 2012 485,486 .

${ }^{2}$ Kato, T.; Okazaki, A.; Hayase, S. Chemical communications. 2005, 363, 3.

3 Yiqing, S.; Gaoquan, S. Polymer Physics. 2013, 231, 51.

${ }^{4}$ Deng, J.; Lu, Q.; Li, H.; Zhang, Y.; Yao, S. RSC Advances. 2015, $29704,5$. XXIV Congresso de Iniciação Científica da UNICAMP 